\title{
Serum Ratio of Leptin to Adiponectin in Patients with Chronic Periodontitis and Type 2 Diabetes Mellitus
}

\author{
Xu Jing Ling, ${ }^{1,2}$ Meng Huan Xin, ${ }^{1}$ He Lu, ${ }^{1}$ Wang Xian'E, ${ }^{1}$ and Zhang Lin ${ }^{3}$ \\ ${ }^{1}$ Department of Periodontology, School and Hospital of Stomatology, Peking University, Beijing 100191, China \\ ${ }^{2}$ Department of Stomatology, Peking University Third Hospital, Beijing 100081, China \\ ${ }^{3}$ Department of Endocrinology, Peking University Third Hospital, Beijing 100191, China
}

Correspondence should be addressed to Meng Huan Xin; kqhxmeng@bjmu.edu.cn

Received 8 September 2013; Accepted 11 December 2013; Published 12 January 2014

Academic Editors: H.-L. Chan, M. L. Kile, and F. Kramer

Copyright (C) $2014 \mathrm{Xu}$ Jing Ling et al. This is an open access article distributed under the Creative Commons Attribution License, which permits unrestricted use, distribution, and reproduction in any medium, provided the original work is properly cited.

\begin{abstract}
Background. Serum ratio of leptin to adiponectin has been reported to be a useful index of insulin resistance. Since these two adipokines could also be involved in many immunoinflammatory reactions, this ratio might be associated with some inflammatory diseases such as periodontitis. The present study aims to explore the difference in serum ratio of leptin/adiponectin among patients with diabetes and periodontitis, patients with periodontitis only, and healthy people and find out the correlation between this ratio and periodontal parameters. Method. 15 patients with chronic periodontitis and type 2 diabetes, 15 patients with chronic periodontitis only, and 15 healthy controls were selected. Clinical indexes and periodontal parameters were recorded and serum leptin and adiponectin levels were tested by ELISA kits. Result. The ratio of leptin/adiponectin is significantly different among three groups; the T2 DM + CP group has the highest ratio $(1.91 \pm 0.48)$ and the healthy group has the lowest ratio $(0.65 \pm 0.13)$. What is more, the ratio of leptin/adiponectin has strong positive correlation with periodontal parameters $(P<0.001)$. Conclusions. Chronic periodontitis could influence the level of adipokines in serum and change the ratio of leptin/adiponectin, and the effect would be enhanced combining with type 2 diabetes.
\end{abstract}

\section{Introduction}

Type 2 diabetes mellitus is a chronic metabolic disease because of insulin resistance, while obesity may be a very important factor associated with insulin resistance and type 2 diabetes mellitus [1]. Researches during the last 20 years showed that the adipose tissue, in addition to being a specialized organ for fat storage and release, should also be considered an active endocrine gland capable of synthesizing and secreting adipokines such as adiponectin and leptin [2]. These adipokines could not only affect the insulin sensitivity, but also be involved in many immunoinflammatory reactions [3].

Chronic periodontitis is an infective disease damaging the periodontal tissue, and the local host response to periodontal pathogens and their products is thought to play a crucial role during this process. Studies recently found that periodontitis might be related to several systemic diseases especially diabetes mellitus [4-6]. Chronic periodontitis and type 2 diabetes could influence themselves bidirectionally because of some common immunoinflammatory mechanisms and some common risk factors such as obesity [7]. Thus, Saito suggested that obesity, type 2 diabetes, and chronic periodontitis are closely associated, exhibiting a triangular relationship [8], and the adipokines might play an important role in this association.

Leptin and adiponectin are two adipocytokines that have been shown to be associated with insulin resistance $[9,10]$. Leptin is a $16-\mathrm{kDa}$ nonglycosylated peptide hormone. It is synthesized mainly in adipocytes and can regulate weight control and modulate other pathophysiological functions such as insulin sensitivity and inflammation [11]. Adiponectin is a 244-residue protein that is produced mainly by white adipose tissue (WAT). Adiponectin increases fatty acid oxidation and reduces the synthesis of glucose in the liver and has been reported to have anti-inflammatory properties [12].

Several studies recently have reported associations between the ratio of leptin/adiponectin and insulin resistance [13-16]. An increased leptin/adiponectin ratio has been 
shown related to insulin resistance in obesity, type 2 diabetes mellitus, or metabolic syndrome.

Since leptin and adiponectin are also involved in the inflammatory process, this biomarker might play some roles in prediction of chronic inflammations. However, the association of leptin/adiponectin ratio in patients with chronic periodontitis and type 2 diabetes mellitus remains unknown. We supposed that the ratio of leptin/adiponectin was different between patients with diabetes mellitus and periodontitis and patients with periodontitis only. Thus, the present study evaluated the difference in serum ratio of leptin/adiponectin among these patients.

\section{Materials and Methods}

2.1. Participant Selection. 30 patients were selected from the clinic of Department of Stomatology, Peking University Third Hospital, Beijing, China, from March 2011 to August 2012. 15 patients were with type 2 diabetes and chronic periodontitis (T2 DM + CP), but without any complications of diabetes; 15 patients were with chronic periodontitis (CP), but systemically healthy. The criteria of chronic periodontitis were signs of clinical inflammation, more than two sites in different quarters with probing depth (PD) $\geq 5 \mathrm{~mm}$ and attachment loss (AL) $\geq 2 \mathrm{~mm}$, and radiographic evidence of bone loss. Patients with type 2 diabetes were diagnosed by Endocrinology Department of Peking University Third Hospital; the criteria of type 2 diabetes were according to the diagnostic criteria from WHO in 1999. 15 healthy subjects were selected from the staff of the hospital, who showed a clinically healthy periodontium, $\mathrm{PD} \leq 3 \mathrm{~mm}, \mathrm{AL}=0$, with no evidence of bone loss on radiographs, and no systemic disease.

The exclusion criteria included: (1) aggressive periodontitis, (2) hypertension, (3) smoking habit, (4) heart diseases, (5) pregnancy, (6) any other systemic disease that can alter the course of periodontal disease, (7) those who had any course of medication affecting periodontal status within 1 month, and (8) those who had received periodontal therapy within 6 months. Informed consent was signed by each volunteer at the beginning of this investigation while the ethical clearance was approved by the Ethical Committee of Peking University.

2.2. Blood Collection. $5 \mathrm{~mL}$ of fasting venous blood was collected from each participator using nonanticoagulated blood tube. After 1-hour clotting at room temperature, serum was separated from blood by centrifuging at $3500 \mathrm{rpm}(r=8 \mathrm{~mm})$ for 15 minutes at $4^{\circ} \mathrm{C}$. Then, the serum was immediately transferred to several Eppendorf tubes and stored at $-70^{\circ} \mathrm{C}$ until the time of assay.

2.3. Leptin and Adiponectin Analysis. The leptin and adiponectin levels were assayed using enzyme linked immunosorbent assay (ELISA) Kit (R\&D, USA) according to the instructions of the manufacturer. Serum samples were diluted 1:100 for adiponectin analyses and 1:10 for leptin analyses. The minimum detection limits were $0.1 \mathrm{ng} / \mathrm{mL}$ for adiponectin and $7.8 \mathrm{pg} / \mathrm{mL}$ for leptin. All samples were duplicated.
2.4. Statistical Analyses. ANOVA one-way variance analysis was performed for comparing the levels of leptin, adiponectin, and ratio of leptin/adiponectin among three groups. The Spearman rank correlation coefficient test was used to investigate the relationship between leptin, adiponectin, or leptin/adiponectin ratio and clinical parameters. All tests were done by SPSS software, and $P$ values $<0.05$ were considered statistically significant.

\section{Results}

The clinical and periodontal parameters of three groups are displayed in Table 1. The T2 DM + CP group consists of 7 males and 8 females, and the mean age is $43.33 \pm 10.08$; the CP group consists of 8 males and 7 females, and the mean age is $43.87 \pm 7.30$; the healthy group consists of 7 males and 8 females, and the mean age is $37.53 \pm 6.37$. There is no significant difference in the age and gender distribution among three groups. The T2DM + CP group and CP group has similar BMI index while the healthy group is lower. The $\mathrm{T} 2 \mathrm{DM}+\mathrm{CP}$ group has higher HbAlc and higher fasting blood glucose (FBG) than CP group and healthy group. Additionally, there is no significant difference in periodontal parameters including $\mathrm{PD}, \mathrm{AL}$, and bleeding index (BI) between T2 DM + CP group and CP group, but these parameters are much lower in healthy group.

The serum concentration of leptin, adiponectin, and the ratio of leptin/adiponectin are shown in Table 2. The level of leptin in serum is highest in T2 DM + CP group and lowest in healthy group, while the level of adiponectin is similar between T2 DM + CP group and CP group but much higher in healthy group. The ratio of leptin/adiponectin is significantly different among three groups; the T2 DM + CP group has the highest ratio and the healthy group has the lowest ratio.

Spearman rank correlation coefficient test between serum level of leptin, adiponectin, and ratio of leptin/adiponectin and $\mathrm{PD}, \mathrm{AL}$, and $\mathrm{BI}$ in all observations was shown in Table 3. The concentration of serum leptin had significant positive correlation with periodontal parameters while the concentration of serum adiponectin had significant negative correlation with periodontal parameters. The ratio of leptin/adiponectin in this study showed strong positive correlation with periodontal parameters $(P<0.001)$.

\section{Discussion}

The present study demonstrated significant difference in leptin, adiponectin, and ratio of leptin/adiponectin among T2 $\mathrm{DM}+\mathrm{CP}$ group, CP group, and healthy group.

The relationship between periodontitis and type 2 diabetes mellitus has been discussed widely in the past several decades. Many studies showed that diabetes is an independent risk factor of chronic periodontitis [17] and periodontitis has been thought to be the sixth complication of diabetes [18], while, on the other hand, periodontitis could worsen the metabolism of diabetes [19]. Although the detail of this bidirectionally association is not clear yet, the cytokines may play an important role during the process [20]. 
TABLE 1: Clinical and periodontal parameters of three groups.

\begin{tabular}{|c|c|c|c|c|c|}
\hline $\begin{array}{l}\text { Characteristics } \\
(\text { mean } \pm S D)\end{array}$ & $\begin{array}{c}\mathrm{T} 2 \mathrm{DM}+\mathrm{CP} \\
(n=15)\end{array}$ & $\begin{array}{c}\mathrm{CP} \\
(n=15)\end{array}$ & $\begin{array}{l}\text { Healthy } \\
(n=15)\end{array}$ & & $P$ value \\
\hline Age (years) & $43.33 \pm 10.08$ & $43.87 \pm 7.30$ & $37.53 \pm 6.37$ & & 0.070 \\
\hline Gender (M/F) & $7 / 8$ & $8 / 7$ & $7 / 8$ & & 0.915 \\
\hline \multirow{3}{*}{ BMI $\left(\mathrm{kg} / \mathrm{m}^{2}\right)$} & \multirow{3}{*}{$24.30 \pm 3.42$} & \multirow{3}{*}{$23.71 \pm 3.78$} & \multirow{3}{*}{$21.19 \pm 3.13$} & $\mathrm{~T} 2 \mathrm{DM}+\mathrm{CP}$ versus $\mathrm{CP}$ & 0.644 \\
\hline & & & & $\mathrm{T} 2 \mathrm{DM}+\mathrm{CP}$ versus $\mathrm{H}$ & 0.018 \\
\hline & & & & $\mathrm{CP}$ versus $\mathrm{H}$ & 0.052 \\
\hline HbAlc (\%) & $7.53 \pm 1.55$ & $5.33 \pm 0.35$ & & & $<0.001$ \\
\hline \multirow{3}{*}{$\mathrm{FBG}(\mathrm{mmol} / \mathrm{L})$} & \multirow{3}{*}{$8.69 \pm 3.80$} & \multirow{3}{*}{$5.41 \pm 0.45$} & \multirow{3}{*}{$4.92 \pm 0.25$} & $\mathrm{~T} 2 \mathrm{DM}+\mathrm{CP}$ versus $\mathrm{CP}$ & $<0.001$ \\
\hline & & & & $\mathrm{T} 2 \mathrm{DM}+\mathrm{CP}$ versus $\mathrm{H}$ & $<0.001$ \\
\hline & & & & $\mathrm{CP}$ versus $\mathrm{H}$ & 0.545 \\
\hline \multirow{3}{*}{$\mathrm{PD}(\mathrm{mm})$} & \multirow{3}{*}{$3.52 \pm 0.76$} & \multirow{3}{*}{$3.93 \pm 0.66$} & \multirow{3}{*}{$2.18 \pm 0.61$} & $\mathrm{~T} 2 \mathrm{DM}+\mathrm{CP}$ versus $\mathrm{CP}$ & 0.106 \\
\hline & & & & $\mathrm{T} 2 \mathrm{DM}+\mathrm{CP}$ versus $\mathrm{H}$ & $<0.001$ \\
\hline & & & & $\mathrm{CP}$ versus $\mathrm{H}$ & $<0.001$ \\
\hline \multirow{3}{*}{$\mathrm{AL}(\mathrm{mm})$} & \multirow{3}{*}{$2.78 \pm 1.91$} & \multirow{3}{*}{$3.29 \pm 1.27$} & \multirow{3}{*}{0} & $\mathrm{~T} 2 \mathrm{DM}+\mathrm{CP}$ versus $\mathrm{CP}$ & 0.297 \\
\hline & & & & $\mathrm{T} 2 \mathrm{DM}+\mathrm{CP}$ versus $\mathrm{H}$ & $<0.001$ \\
\hline & & & & $\mathrm{CP}$ versus $\mathrm{H}$ & $<0.001$ \\
\hline \multirow{3}{*}{ BI } & \multirow{3}{*}{$2.53 \pm 0.77$} & \multirow{3}{*}{$2.91 \pm 0.75$} & \multirow{3}{*}{$0.69 \pm 0.46$} & $\mathrm{~T} 2 \mathrm{DM}+\mathrm{CP}$ versus $\mathrm{CP}$ & 0.130 \\
\hline & & & & $\mathrm{T} 2 \mathrm{DM}+\mathrm{CP}$ versus $\mathrm{H}$ & $<0.001$ \\
\hline & & & & $\mathrm{CP}$ versus $\mathrm{H}$ & $<0.001$ \\
\hline
\end{tabular}

BMI: body mass index; FBG: fasting blood glucose; PD: probing depth; AL: attachment loss; BI: bleeding index.

TABLE 2: Serum leptin and adiponectin levels of three groups.

\begin{tabular}{|c|c|c|c|c|c|}
\hline $\begin{array}{l}\text { Characteristics } \\
(\text { mean } \pm \text { SD) }\end{array}$ & $\begin{array}{c}\mathrm{T} 2 \mathrm{DM}+\mathrm{CP} \\
(n=15)\end{array}$ & $\begin{array}{c}\mathrm{CP} \\
(n=15)\end{array}$ & $\begin{array}{l}\text { Healthy } \\
(n=15)\end{array}$ & & $P$ value \\
\hline \multirow{3}{*}{ Leptin (ng/mL) } & \multirow{3}{*}{$8.30 \pm 2.21$} & \multirow{3}{*}{$6.46 \pm 1.74$} & \multirow{3}{*}{$4.46 \pm 1.04$} & $\mathrm{~T} 2 \mathrm{DM}+\mathrm{CP}$ versus $\mathrm{CP}$ & 0.006 \\
\hline & & & & $\mathrm{T} 2 \mathrm{DM}+\mathrm{CP}$ versus $\mathrm{H}$ & $<0.001$ \\
\hline & & & & $\mathrm{CP}$ versus $\mathrm{H}$ & 0.003 \\
\hline \multirow{3}{*}{ Adiponectin $(\mu \mathrm{g} / \mathrm{mL})$} & \multirow{3}{*}{$4.43 \pm 0.96$} & \multirow{3}{*}{$4.77 \pm 1.10$} & \multirow{3}{*}{$6.95 \pm 1.21$} & $\mathrm{~T} 2 \mathrm{DM}+\mathrm{CP}$ versus $\mathrm{CP}$ & 0.403 \\
\hline & & & & $\mathrm{T} 2 \mathrm{DM}+\mathrm{CP}$ versus $\mathrm{H}$ & $<0.001$ \\
\hline & & & & $\mathrm{CP}$ versus $\mathrm{H}$ & $<0.001$ \\
\hline \multirow{3}{*}{ Leptin/adiponectin ratio } & \multirow{3}{*}{$1.91 \pm 0.48$} & \multirow{3}{*}{$1.42 \pm 0.47$} & \multirow{3}{*}{$0.65 \pm 0.13$} & $\mathrm{~T} 2 \mathrm{DM}+\mathrm{CP}$ versus $\mathrm{CP}$ & 0.002 \\
\hline & & & & $\mathrm{T} 2 \mathrm{DM}+\mathrm{CP}$ versus $\mathrm{H}$ & $<0.001$ \\
\hline & & & & $\mathrm{CP}$ versus $\mathrm{H}$ & $<0.001$ \\
\hline
\end{tabular}

TABLE 3: Results of Spearman rank correlation coefficient test.

\begin{tabular}{|c|c|c|c|c|c|c|}
\hline \multirow{2}{*}{ Characteristics } & \multicolumn{2}{|c|}{ Leptin } & \multicolumn{2}{|c|}{ Adiponectin } & \multicolumn{2}{|c|}{$\mathrm{L} / \mathrm{A}$ ratio } \\
\hline & $r$ & $P$ & $r$ & $P$ & $r$ & $P$ \\
\hline $\mathrm{PD}$ & 0.420 & 0.004 & -0.543 & 0.002 & 0.508 & $<0.001$ \\
\hline $\mathrm{AL}$ & 0.565 & $<0.001$ & -0.484 & 0.001 & 0.610 & $<0.001$ \\
\hline $\mathrm{BI}$ & 0.559 & $<0.001$ & -0.501 & $<0.001$ & 0.609 & $<0.001$ \\
\hline
\end{tabular}

PD: probing depth; AL: attachment loss; BI: bleeding index.

In our present study, patients in $\mathrm{CP}$ group had higher level of leptin, lower level of adiponectin, and higher leptin/adiponectin ratio in serum than healthy people, while patients in T2 DM + CP group had even higher level of leptin and similar level of adiponectin compared to CP group, and their ratio of leptin/adiponectin was the highest among three groups, which meant that chronic periodontitis could influence the level of adipokines in serum and change the leptin/adiponectin ratio, and the effect would be enhanced combining with type 2 diabetes.

Adiponectin has insulin-sensitizing and anti-inflammatory properties [2]. It inhibits IL-6 and TNF- $\alpha$ production 
by macrophages and increases the production of important anti-inflammatory factors such as IL-10 or IL-1RA by human monocytes, macrophages, and dendritic cells [21].

leptin plays an important role in the process of insulin sensitivity regulation and could be a proinflammatory factor [2]. It stimulates the immune system by enhancing proinflammatory cytokine production and phagocytosis by macrophages [11]. Therefore, during infection and inflammation, leptin expression is modulated in a manner similar to the cytokine response to infection and injury and could increase in some inflammatory diseases such as periodontitis $[22,23]$.

According to the different properties of adiponectin and leptin, some researches recently found that the ratio of leptin/adiponectin could be a useful index of insulin resistance [13-16]. The ratio of leptin/adiponectin correlates with glucose infusion rate (GIR) more closely than leptin and adiponectinalone or HOMA-R [16].

The inflammatory mechanism has now been considered to be an important part of the pathogen of diabetes and be closely linked with insulin resistance. The increasing of inflammatory cytokines such as TNF- $\alpha$, IL1- $\beta$, and IL-6 could impair insulin signaling pathways as well as reduce the function of mitochondria and result in insulin resistance [24].

In our investigation, strong correlations were observed between the ratio of leptin/adiponectin and periodontal parameters. This phenomenon suggests potential relationship between periodontal inflammation and insulin resistance while further studies in larger populations are required.

\section{Conclusion}

In conclusion, chronic periodontitis could influence the level of adipokines in serum and change the ratio of leptin/adiponectin, and the effect would be enhanced combining with type 2 diabetes. What is more, the ratio of leptin/ adiponectin had strong positive correlation with periodontal parameters and gave a hint of potential relationship between periodontal inflammation and insulin resistance.

\section{Conflict of Interests}

The authors declare that there is no conflict of interests regarding the publication of this paper.

\section{References}

[1] B. L. Wajchenberg, "Subcutaneous and visceral adipose tissue: their relation to the metabolic syndrome," Endocrine Reviews, vol. 21, no. 6, pp. 697-738, 2000.

[2] P. Arner, "Insulin resistance in type 2 diabetes: role of the adipokines," Current Molecular Medicine, vol. 5, no. 3, pp. 333-339, 2005.

[3] E. E. Kershaw and J. S. Flier, "Adipose tissue, adipokines, and inflammation," Journal of Allergy and Clinical Immunology, vol. 115, pp. 911-919, 2005.

[4] F. O. Costa, L. O. Miranda Cota, E. J. Pereira Lages et al., "Progression of periodontitis and tooth loss associated with glycemic control individuals under periodontal maintenance
Therapy: a 5-Year follow-up Study," Journal of Periodontology, vol. 84, pp. 595-605, 2013.

[5] H. Loe, "Periodontal disease: the sixth complication of diabetes mellitus," Diabetes Care, vol. 16, no. 1, pp. 329-334, 1993.

[6] L. P. Lim, F. B. K. Tay, C. F. Sum, and A. C. Thai, "Relationship between markers of metabolic control and inflammation on severity of periodontal disease in patients with diabetes mellitus," Journal of Clinical Periodontology, vol. 34, no. 2, pp. 118-123, 2007.

[7] S. G. Grossi and R. J. Genco, "Periodontal disease and diabetes mellitus: a two-way relationship," Annals of Periodontology, vol. 3, no. 1, pp. 51-61, 1998.

[8] T. Saito and Y. Shimazaki, "Metabolic disorders related to obesity and periodontal disease," Periodontology, vol. 43, no. 1, pp. 254-266, 2007.

[9] K. Hotta, T. Funahashi, N. L. Bodkin et al., "Circulating concentrations of the adipocyte protein adiponectin are decreased in parallel with reduced insulin sensitivity during the progression to type 2 diabetes in rhesus monkeys," Diabetes, vol. 50, no. 5, pp. 1126-1133, 2001.

[10] S. Gulturk, A. Cetin, and S. Erdal, "Association of leptin with insulin resistance, body composition, and lipid parameters in postmenopausal women and men in type 2 diabetes mellitus," Saudi Medical Journal, vol. 29, no. 6, pp. 813-820, 2008.

[11] R. S. Ahima and J. S. Flier, "Leptin," Annual Review of Physiology, vol. 62, pp. 413-437, 2000.

[12] F. Lago, R. Gómez, J. J. Gómez-Reino et al., "Adipokines as novel modulators of lipid metabolism," Trends in Biochemical Sciences, vol. 34, pp. 500-510, 2009.

[13] M. Tajtakova, D. Petrasova, A. Pidanicova, A. Gallovicova, C. Blanarova, and J. Petrovicova, "Serum levels of leptin, adiponectin, retinol binding protein 4 and leptin/adiponectin molar ratio as another possible marker of insulin resistance in obese," Bratislava Medical Journal, vol. 111, no. 4, pp. 212-215, 2010.

[14] J. Zaletel, D. Pongrac Barlovic, and J. Prezelj, "Adiponectinleptin ratio: a useful estimate of insulin resistance in patients with type 2 diabetes," Journal of Endocrinological Investigation, vol. 33, no. 8, pp. 514-518, 2010.

[15] B. Thorand, A. Zierer, J. Baumert, C. Meisinger, C. Herder, and W. Koenig, "Associations between leptin and the leptin/ adiponectin ratio and incident Type 2 diabetes in middle-aged men and women: results from the MONICA/KORA Augsburg Study 1984-2002," Diabetic Medicine, vol. 27, no. 9, pp. 10041011, 2010.

[16] N. Oda, S. Imamura, T. Fujita et al., "The ratio of leptin to adiponectin can be used as an index of insulin resistance," Metabolism, vol. 57, no. 2, pp. 268-273, 2008.

[17] F. O. Costa, L. O. Miranda Cota, E. J. Pereira Lages et al., "Progression of periodontitis and tooth loss associated with glycemic control individuals under periodontal maintenance Therapy: a 5-Year follow-up Study," Journal of Periodontology, vol. 84, pp. 595-605, 2013.

[18] H. Loe, "Periodontal disease: the sixth complication of diabetes mellitus," Diabetes Care, vol. 16, no. 1, pp. 329-334, 1993.

[19] L. P. Lim, F. B. K. Tay, C. F. Sum, and A. C. Thai, "Relationship between markers of metabolic control and inflammation on severity of periodontal disease in patients with diabetes mellitus," Journal of Clinical Periodontology, vol. 34, no. 2, pp. 118-123, 2007. 
[20] S. G. Grossi and R. J. Genco, "Periodontal disease and diabetes mellitus: a two-way relationship," Annals of periodontology, vol. 3, no. 1, pp. 51-61, 1998.

[21] H. Tilg and A. R. Moschen, "Adipocytokines: mediators linking adipose tissue, inflammation and immunity," Nature Reviews Immunology, vol. 6, no. 10, pp. 772-783, 2006.

[22] B. V. Karthikeyan and A. R. Pradeep, "Gingival crevicular fluid and serum leptin: their relationship to periodontal health and disease," Journal of Clinical Periodontology, vol. 34, no. 6, pp. 467-472, 2007.

[23] Y. Y. Liu, X. Zhang, D. Shi et al., "Association between plasma leptin level and periodontal parameters in patients with aggressive periodontitis," Zhonghua Kou Qiang Yi Xue Za Zhi, vol. 48, pp. 3-6, 2013.

[24] S. M. Hirabara, R. Gorjão, M. A. Vinolo et al., "Molecular targets related to inflammation and insulin resistance and potential interventions," Journal of Biomedicine and Biotechnology, vol. 2012, Article ID 379024, 16 pages, 2012. 


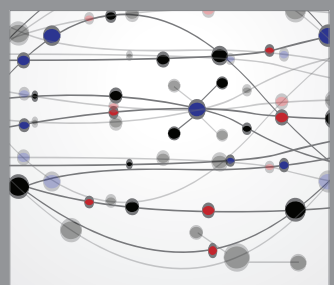

The Scientific World Journal
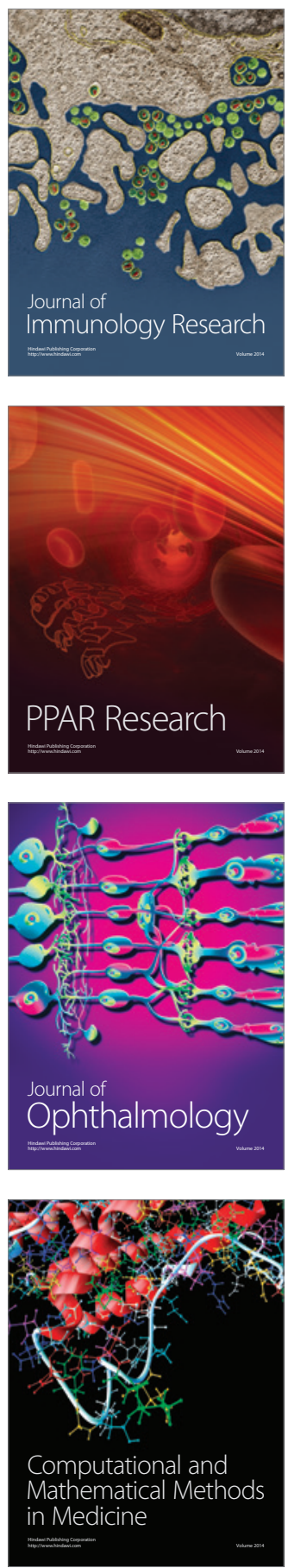

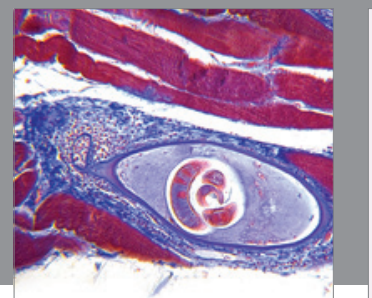

Gastroenterology

Research and Practice
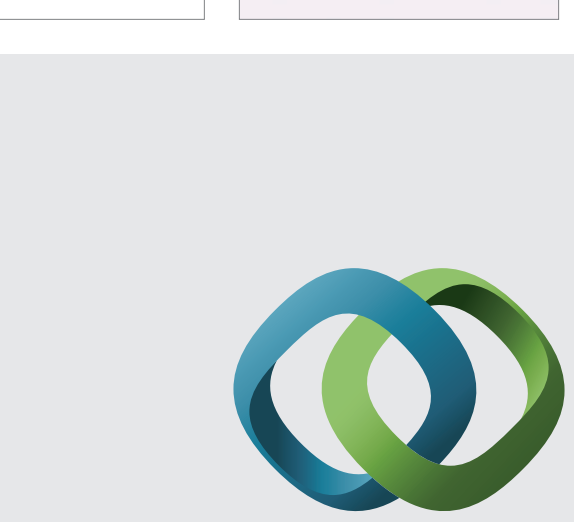

\section{Hindawi}

Submit your manuscripts at

http://www.hindawi.com
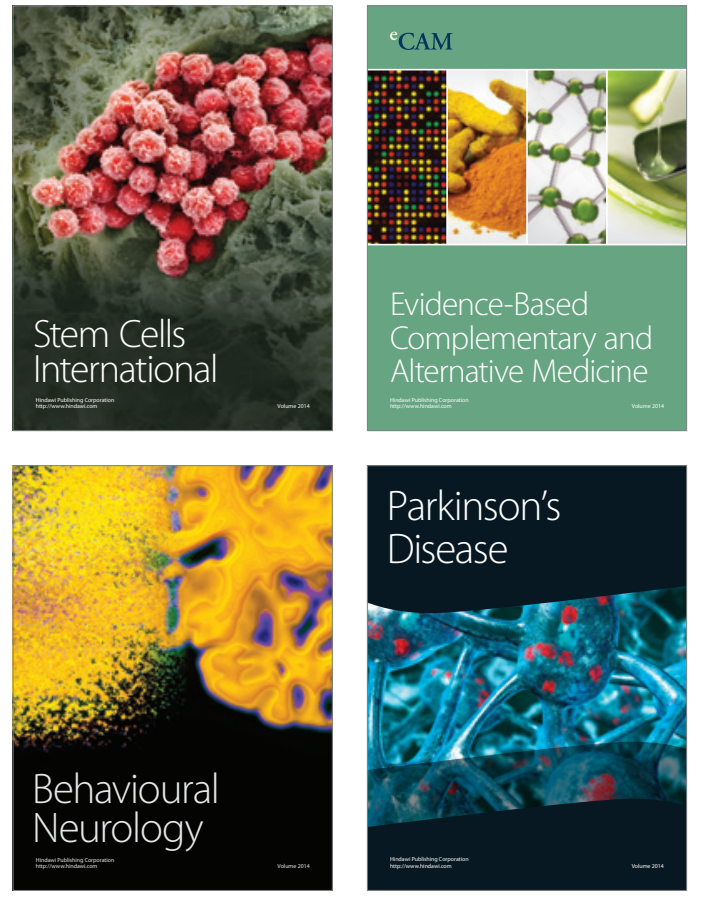
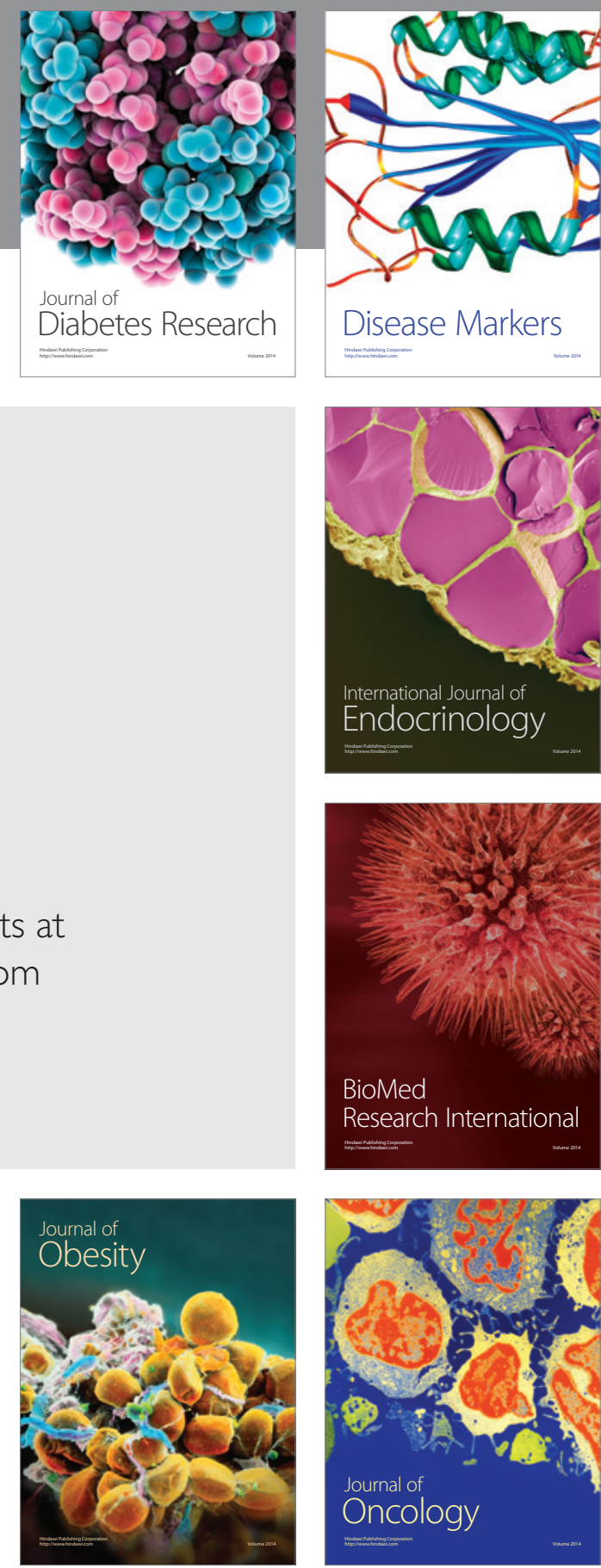

Disease Markers
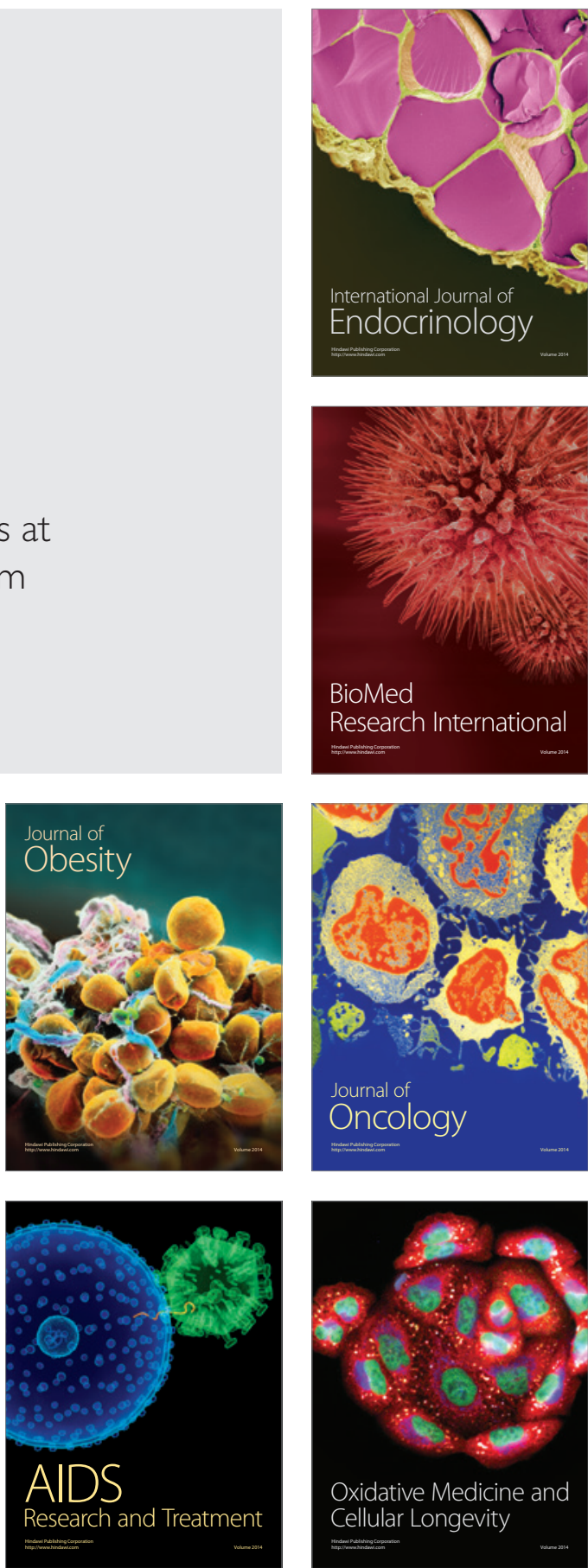